\title{
The Peer to Peer Social Fabric as a Platform for General Collective Intelligence
}

Andy E. Williams

Nobeah Foundation, Nairobi, Kenya

\begin{abstract}
INTRODUCTION: General Collective Intelligence or GCI has been defined as a platform that combines individuals into a collective intelligence with the potential for exponentially greater general problemsolving ability (intelligence) than that of any individual in the group. Cognitive computing applications are executed by intelligent agents on a user's behalf to optimize individual user outcomes. Cognitive computing platforms are executed by individuals organized by a GCI to achieve greater collective outcomes. The Peer to Peer Social Fabric (P2PSF) is an infrastructure platform proposed to enable the execution of cognitive computing applications or platforms.

OBJECTIVES: To explore the functionality required by an infrastructure platform with the capacity to enable the operation of cognitive computing applications or platforms. And to determine whether the functionality of the proposed Peer to Peer Social Fabric is sufficient.

METHODS: The requirements of collective cognitive computing were assessed, including the requirement to increase capacity for complexity, capacity to scale number of processes, and capacity to sustain processes. The proposed high-level specifications of the Peer to Peer Social Fabric were compared to those requirements to determine whether that functionality is sufficient.

RESULTS: The proposed Peer to Peer Social Fabric appears to meet the requirements of both the operating system for GCI, as well as the requirements of a client enabling individuals and organizations to access either AGI or GCI functionality.

CONCLUSION: All of the functionality required by he Peer to Peer Social Fabric might already exist, but an understanding of how that functionality must be combined in order to achieve the exponential increase in general problem-solving ability potentially possible through AGI or GCI is a new and important contribution.
\end{abstract}

Keywords: General Collective Intelligence, Human-Centric Functional Modelling, Artificial General Intelligence, Peer to Peer Social Fabric

\section{Introduction}

General Collective Intelligence is fundamentally different from every current group decisionmaking process in that it creates a single welldefined thread of collective reasoning that optimizes outcomes independently from the control of any subset of actors within or outside the group. Where current decision-making tools or processes cannot be reliably separated from being aligned with the interests of their designers, owners, and other decision-makers, being driven by the collective cognition a General Collective Intelligence platform is reliably aligned with the collective interests of the group. Defining GCI by analogy, Artificial Intelligence is to Collective Intelligence what Artificial General Intelligence (AGI) is to General Collective Intelligence (GCI).
In practice, the uniqueness of GCI is the capacity to execute self-organizing processes that might enable groups to self-assemble into potentially massive networks of cooperation that radically increase general problem-solving ability. Groups have been proposed by other researchers to have an innate "general collective intelligence factor" [9] describing the general problem-solving ability of groups, by contrast Collective Intelligence (CI) solutions have narrow problem-solving ability wherever they lack the capacity to address any general problem. General Collective Intelligence or GCI platforms on the other hand have the functions that are defined by a functional model of collective cognition as being required to achieve general problem-solving ability within the group, as well as to greatly increase this factor [1], [2]. 
A functional modelling approach might be used to decouple software in any domain into a library of implementations of a minimal set of functions. From this perspective GCI is a "cognitive computing platform" that has the potential to execute those functions for a group of users in any way that maximizes capacity to solve collective problems in that domain. From this same perspective an intelligent agent executing those functions for a single user in any way that maximizes their capacity to solve individual problems in that domain is a "cognitive computing application".

This paper explores the requirements of software infrastructure with the capacity to facilitate the operations of cognitive computing applications or platforms, and therefore explores the infrastructure required to implement a GCI. Since GCI is very new, to the author's knowledge no other work has explored this question.

\section{Related Work}

Though a model of the innate general problem solving ability of groups exists [8], no other model of a platform giving groups general problemsolving ability exists. As mentioned, this model of GCI is based on a functional modelling approach that enabled a model of collective cognition to be developed from first principles. Though others have described the concept of a collective super intelligence, as well as methodologies to potentially achieve it [10], to the author's knowledge the author's own work is the only computational model that defines the specific mechanisms required for a GCI to have the capacity to achieve super intelligence in that general collective intelligence factor. Because of this, because the model is derived from first principles, and because this model is so new, all of the existing literature surrounding GCI refers to the author's own published work, or to pre-prints of the author's unpublished work that are still under review.

\section{Research Questions and Approach}

The research questions addressed in this paper are approached with the method described below:

Section 3: Research Questions Addressed

3.1. What is the functionality required by an infrastructure platform with the capacity to facilitate the operations of cognitive computing applications or platforms?

3.2. Does the proposed Peer to Peer Social Fabric provide this functionality?

Section 4: Model

4.1. Defining a model for collective cognition.

4.2. Defining the functionality required for collective cognitive computing and scaling collective cognitive computing capacity in terms of capacity for complexity, capacity for cooperation, and capacity to scale and sustain rate of processing

\section{Section 5. Method}

5.1. The mechanisms required to scale capacity to collectively navigate complexity were assessed.

5.2. The mechanisms required to scale cooperation were assessed.

5.3. The mechanisms required to scale and sustain rate of processing were assessed.

5.4. The requirements of cognitive computing applications and platforms were assessed to determine if the proposed functionality of the Peer to Peer Social Fabric was sufficient.

Section 6. Findings

Section 7. Research Limitations

Section 8. Practical Implications

Section 9. Conclusions

\section{Model}

While the term "collective cognition" is frequently used to indicate some innate capabilities of groups of humans, animals [23], or organizations [24], [25], in this context it is a hypothetical platform that provides groups with the capacity to navigate collective reasoning processes coherently.

\subsection{Defining a model for collective cognition}


A General Collective Intelligence or GCI is a hypothetical platform that combines groups into a virtual collective cognition with a single welldefined thread of collective reasoning. Defining it by analogy, Artificial Intelligence is to Collective Intelligence what Artificial General Intelligence (AGI) is to General Collective Intelligence (GCI). Since an entity with a well-defined cognition with it's own independent thread of reasoning must behave as an independent actor, GCI is a radically different concept from Collective Intelligence (CI) solutions, which are essentially collective decision-making tools controlled by some subset of actors within or outside the group.

In order to execute this model of GCI, information and processes must be represented in terms of a common semantic model so that problems can be universally understood and so that solutions can be universally compared and the most fit solutions identified. This common semantic model involves defining a "conceptual space" and representing information as points in that conceptual space, as well as defining reasoning as paths in that space. As described in more detail elsewhere [2], [7], the model of GCI itself is an adaptive problem-solving system that navigates the collective conceptual space.

As shown in figure 1, using the concept of an accessible conceptual space, and the concept of the resolution of concepts in that accessible conceptual space, the underlying semantic model of information and reasoning processes provides an objective definition for problems that are not reliably definable by any individual, and solutions that are not reliably discoverable by any individual.

Figure 1. Top-left: problems in which the concepts lie outside of accessible conceptual space are not definable. Top-right: problems for which the conceptual space lacks sufficient resolution are unsolvable. Bottom-left: solutions for which the concepts lie outside of accessible conceptual space are not discoverable. Bottomright: solutions for which the conceptual space lacks sufficient resolution are incomprehensible.

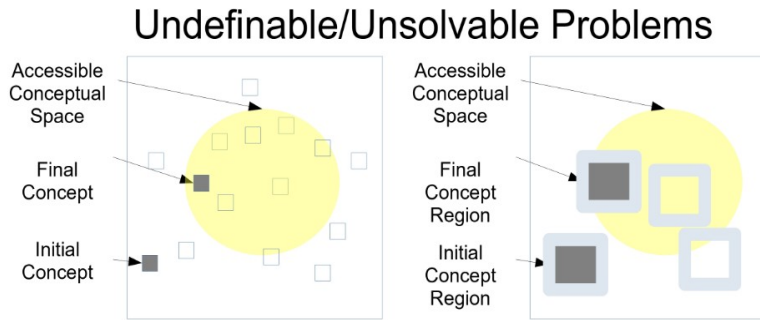

Undiscoverable/Incomprehensible Solutions
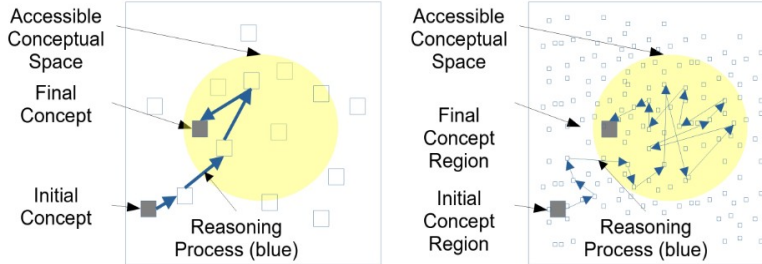

4.1. Defining the functionality required for collective cognitive computing and scaling collective cognitive computing capacity in terms of capacity for complexity, capacity for cooperation, and capacity to scale and sustain rate of processing

In conceptual space a problem is defined as the lack of a path from an initial concept to a final concept. General problem-solving ability (intelligence) is the volume of conceptual space that can be navigated per unit time. General problem-solving ability is increased by increasing the size of the collectively accessible conceptual space, by increasing the resolution at which points in conceptual space can be located, and by increasing the rate at which the collective conceptual space can be navigated as well as increasing ability to sustain that navigation, so problems that are not reliably definable by any individual might reliably be defined by the group, and so that solutions that are not reliably discoverable by any individual might reliably be discovered by the group.

The cognitive domain is just one of a number of other adaptive domains defined by the Functional Modelling Framework for representing the human system [2],[7]. Some of these other adaptive domains are standalone systems (body, emotions, cognition, consciousness). Others (cooperation, reproduction, etc.) overlap and can be applied to reasoning in the cognitive domain, or can be applied to the other standalone domains. One of these overlapping domains is the domain of 
cooperation. In an individual cognition this domain removes the limits to the number of functional components that can be engaged in the reasoning process. In collective cognition this domain removes the limits to the number of participants that can be engaged. Where outcomes of reasoning can be scaled by executing more reasoning processes in parallel or in series, this potentially removes the limit to scaling impact on any outcomes that might be achieved through that reasoning.

Another example of an adaptive domain is reproduction. In a GCI based process of reproduction, solutions must be reproduced in a way that introduces enough difference to solve a problem, but not so much difference as to break compatibility with a potentially complex network of processes containing many chains of cooperation [12]. A network of cooperation can be a physical network, or it can be a network of reasoning processes in the cognitive domain. In any case, outcomes must be optimized across all chains of cooperation using some methodical approach towards maximizing compatibility in reproducing the solution, such as with a reproduction algorithm. This concept of a reproduction algorithm is still being explored.

From a functional modelling perspective, the functionality required for collective cognitive computing is a subset of the functionality required to have the capacity to solve any general problem. That is, the functions required to navigate the collective conceptual space, and the functions required to do so with general problem-solving ability. While actual implementations of these functions remain to be elaborated, approximations of these functions have been defined [15].

Collective cognition has the potential to exponentially scale general problem-solving ability over that of any individual [5]. Defining cognitive computing capacity in terms of capacity for complexity, capacity for cooperation, and capacity to scale and sustain rate of processing, as described later in this paper, and assuming collective cognition can exponentially scale general problem-solving ability, then collective collective cognitive computing would be expected to have the potential to exponentially scale cognitive computing capacity expressed in terms of capacity for complexity, capacity for cooperation, and capacity to scale and sustain rate of processing.

\section{Method}

This technical article is intended as an original report on specialist technical work. The research questions were addressed using the methods summarized in table 1 .

Table 1. Research questions and methods.

\begin{tabular}{|c|c|}
\hline Research Question & Method \\
\hline $\begin{array}{l}\text { 1. What is the } \\
\text { functionality required } \\
\text { by an infrastructure } \\
\text { platform with the } \\
\text { capacity to facilitate the } \\
\text { operations of cognitive } \\
\text { computing applications } \\
\text { and platforms? }\end{array}$ & $\begin{array}{l}\text { 1. The } \\
\text { mechanisms } \\
\text { required to scale } \\
\text { complexity were } \\
\text { assessed. } \\
2 . \text { The } \\
\text { mechanisms } \\
\text { required to scale } \\
\text { cooperation were } \\
\text { assessed. } \\
\text { 3. The } \\
\text { mechanisms } \\
\text { required to scale } \\
\text { rate of processing } \\
\text { and sustainability } \\
\text { were assessed. }\end{array}$ \\
\hline $\begin{array}{l}\text { 2. Does the proposed } \\
\text { Peer to Peer Social } \\
\text { Fabric provide this } \\
\text { functionality? }\end{array}$ & $\begin{array}{l}\text { 4. The } \\
\text { requirements of } \\
\text { cognitive } \\
\text { computing } \\
\text { applications and } \\
\text { platforms were } \\
\text { assessed to } \\
\text { determine if the } \\
\text { proposed } \\
\text { functionality of } \\
\text { the Peer to Peer } \\
\text { Social Fabric was } \\
\text { sufficient. }\end{array}$ \\
\hline
\end{tabular}


5.1. What is the functionality required by an infrastructure platform with the capacity to facilitate the operations of cognitive computing applications or platforms?

Based on functional models being implementation independent, the functionality required by an intelligent agent using general problem-solving ability to maximize outcomes for individual users through cognitive computing applications, is in a general way expected to be the same functionality required by a GCI to maximize collective outcomes for groups of individuals in cognitive computing platforms. For this reason, only the question of which infrastructure is required for cognitive computing platforms was addressed. This question was addressed as below.

\section{Using GCI to Scale Collective Outcomes through Scaling Capacity to Manage Complexity of Problem Definitions and Solutions}

As mentioned, in a GCI a problem is a gap between a point in the collective conceptual space that represents one concept, and a point in the collective conceptual space that represents another concept. A solution is a set of reasoning processes that form a path between those two points. Where the sequence of reasoning processes required to solve a problem is longer than can reliably be navigated by any individual cognition, and/or contains points defined at a higher resolution (smaller region in conceptual space) than can reliably be navigated by any individual cognition, then the problems are too complex to be defined and solutions are too complex to be discovered without an increase in general problem-solving ability (intelligence) such as achievable through GCI.

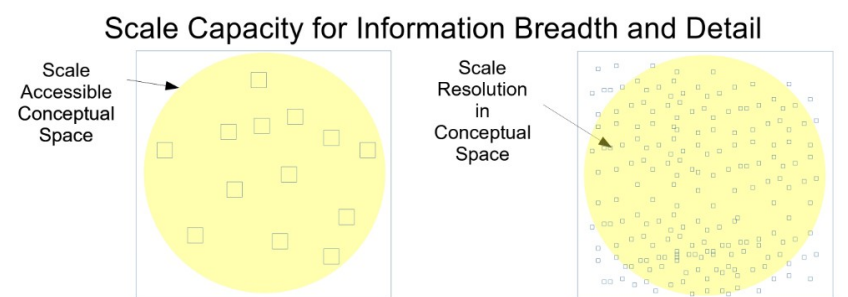

Scale Capacity for Length and Complexity of Processing
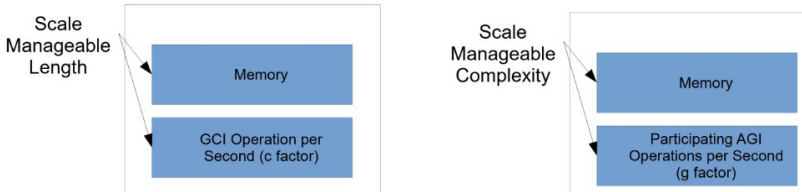

Figure 2. Top-left: scale capacity for information breadth by increasing the accessible conceptual space. Top-right: scale capacity for information detail by increasing the resolution of conceptual space. Bottom-left: scale capacity for length of processing within acceptable time frames by scaling memory and operations per second of the GCI orchestrating collective processing (c factor). Bottom-right: scale capacity for complexity that can be navigated within acceptable time frames by scaling memory and operations per second of the AGI participating in collective processing ( $\mathrm{g}$ factor).

In a GCI, scaling the complexity of problems that can be defined or solved over the capacity of any individual involves creating the capacity to add each individual's capacity for complexity to the collective capacity for complexity. In terms of the collective conceptual space this equates in part to increasing the size of the accessible conceptual space to include the conceptual space of all users. Since resolution in conceptual space is determined by the number of relationships with other concepts that fix each concept's position in conceptual space more precisely, increasing capacity for complexity also includes increasing the resolution in conceptual space to that possible with the relationships between concepts that can be defined by all users. Increasing capacity for complexity that can be navigated within acceptable time frames also includes scaling memory and operations per second of both the GCI and the intelligent agents (AGI) potentially representing each user. Increasing the collective conceptual space to include the conceptual space of all users equates to creating a collective cognition (GCI) that is able to navigate the collective conceptual space with general problem-solving ability. Resolution in conceptual space is defined by the number of relationships of each concept with other concepts in a functional model of cognition. Increasing the resolution in conceptual space to that possible with all users involves again defining a collective cognition (GCI) able to navigate all relationships defined by any individual. Since relationships are defined by the individual's conceptual space, this again equates to creating a 
collective cognition (GCI) that is able to navigate the collective conceptual space with general problem-solving ability. Once this GCI is implemented, the third aspect of complexity (processing speed and memory) might be addressed through simply running the GCI on more powerful hardware.

The functionality required to increase the complexity of problems that can be defined or solved is then that required to create the capacity to potentially incorporate all the information and reasoning processes possessed by every individual in the group and to navigate that information and reasoning with general-problem-solving ability. Since GCI potentially defines a collective cognition with general problem-solving ability [7], then GCI can potentially increase capacity of the group to navigate complexity.

\section{Using GCI to Scale Collective Outcomes through Scaling Capacity for Cooperation}

Assume that simple cooperation between two parties can be represented by a first order barter transaction in which one entity exchanges some value in return for the other party exchanging an approximately equal value. And assume that complex cooperation can be represented by Nth order barter transactions in which the first party gives something to the second party, who gives something to the third party, and so on until the N1 th party gives something to the Nth party. Nth order barter transactions can enable a GCI to optimize collective outcomes over an unlimited number of possible chains of cooperation, to the capacity of the cooperating entities to engage in that cooperation. In an open Nth order barter transaction, value is provided to the first party from outside the chain of cooperation. This cooperation can potentially be applied to the execution of any process.

Figure 3. Scale outcomes of processing through scaling process execution in sequence and in parallel.

In a GCI, scaling the capacity for cooperation over that which might be orchestrated by any individual involves creating the capacity to add
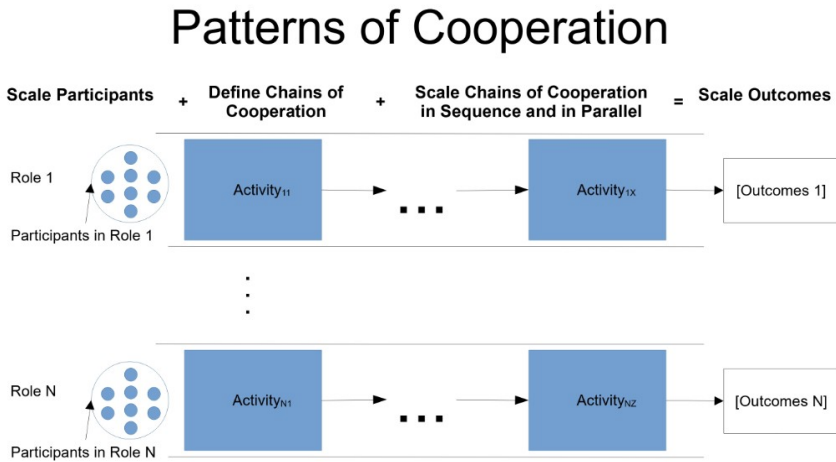

each individual's capacity for cooperation to the collective capacity for cooperation. This equates in part to taking every chain of cooperation defined in every individual's conceptual space, and defining every possible combination to form larger chains of cooperation in the collective conceptual space. It also equates in part to the capacity to determine which chain of cooperation is most "fit" in achieving collectively targeted outcomes so that any cooperation might reliably converge on a single process per targeted outcome.

The functionality required by GCI to increase capacity for cooperation is that required to create the capacity to potentially incorporate all individuals or other entities, as well as all of their computing devices or other resources. This functionality in turn is that required to create the capacity to potentially incorporate all the information and reasoning processes possessed by every individual in the group and to navigate that information and reasoning with general-problemsolving ability. Since this has been defined as part of the functionality of GCI [7], then GCI potentially can increase capacity of the group to negotiate cooperation.

\section{Using GCI to Scale Collective Outcomes through Scaling Capacity for Processing Rate and Sustainability}

In a GCI, general problem-solving ability is the volume of collective conceptual space that can be navigated per unit time. Wherever a given chain of cooperation achieves some positive outcome, that outcome can always be increased to any arbitrary level, within the capacity of the system of cooperating entities to engage in cooperation, 
and within the capacity to increase the size of networks of cooperation in which outcomes are aligned. By removing the limits to the size of networks within which cooperation might be aligned, the magnitude of value they can create and the rate at which they can create it can reliably be increased to the point that is sufficient for cooperation to be self-sustaining. Since the processes that can potentially be involved in this cooperation are those of of any entity in the collective, as opposed to being limited to those of any entity to which decision-making has been centralized, the limits on opportunities to create value by aligning outcomes of processes can be removed.

The functionality required by GCI to increase capacity for sustainability is that required to create the capacity to engage all individuals in processes combined into networks of cooperation [12] that create sufficient value at a sufficient rate to be self-sustaining. This functionality in turn is that required to create the capacity to potentially incorporate all the information and reasoning processes possessed by every individual in the group and to navigate that information and reasoning with general-problem-solving ability. Since this has been defined as part of the functionality of GCI [7], then GCI potentially can increase capacity of the group to scale problemsolving rate and sustainability.

\subsection{Does the proposed Peer to Peer Social Fabric provide this functionality?}

This research question was addressed as below.

\section{Infrastructure Required for Scaling Outcomes}

A collective reasoning process executed by a GCI can be represented as consisting of $\mathrm{N}$ activities, each of which is executed by one of $M$ participants. In order for each individual to participate in that collective reasoning, any attributes of processing used to execute activity "i" must be passed as input where required to the participant executing activity " $i+1$ ".

In order to increase the complexity of problems that can be defined or solved by potentially incorporating all the information and reasoning processes possessed by every individual in the group, in order to increase capacity for cooperation by potentially incorporating all individuals, all computing devices, and incorporating any other resources in processing, and in order to increase capacity for sustainability by engaging all individuals in processes that create sufficient value at a sufficient rate to be self-sustaining, all attributes of processing must be virtualized so they can be passed between individuals in this way.

For example, a GCI must be able to transfer a process to a different physical context of execution so it might be executed on a more powerful machine that just became available. Or if a process represents a service, a GCI must be able to transfer responsibility to a different owner so that the process might be executed by that individual while enabling the individual to own the outcomes so they can be incentivized to participate in that execution.

This requires defining all attributes of processing to be virtual so that implementations of all these attributes can be assigned by the GCI. Having decoupled the physical context of execution, as well as having decoupled identity, ownership, and potentially other properties of execution, then these properties might be made portable within a client so they might be applied to any cognitive computing application used by an individual. Or these properties might be made portable within a universally available infrastructure platform so that they might be applied to processes executed collectively by a group of users, by a group of intelligent agents working on each user's behalf, or some combination of the two, within any cognitive computing platform running on that infrastructure platform.

The required infrastructure for a cognitive computing application is then a portable repository of identities, physical contexts of execution, and other virtualized attributes of processes that places those attributes in the user's sole control and that might be applied to any software domain to create a cognitive computing 
application. For example, in the case that a single user of two software applications, rather than having an identify belonging to application A, and sharing that identity with application $\mathrm{B}$, which might mean the provider of application $\mathrm{A}$ has the ability to compromise application $\mathrm{B}$, in such a portable repository the identity belongs to the individual's repository. Since both application A and application B are running in the same user's repository, in transferring execution to application $\mathrm{B}$ the repository might just transfer that portable identity of the user.

Such functionality is not necessarily new, but a semantic model (self-contained definition) of such attributes as required to decouple them from being defined by any centralized repository, is new and potentially impactful. Because a functional approach to AGI and GCI must be independent of any implementation, this would provide a universal standard for portability. And since the impact of a universal standard for portability would enable the maximization of individual or collective outcomes that is possible with GCI, this is significant and new.

The required infrastructure for a cognitive computing platform that might be used by groups is similarly a portable repository of identities, physical contexts of execution, and other attributes that are in the user's sole control and which might be applied to collective processing in any software domain to create a cognitive computing platform.

The Peer to Peer Social Fabric (P2PSF) is a proposed design for such a platform. While the functionality involved is broad and ambitious, using a GCI based approach to design enables needed components in existing products or services to be identified so they can be reused from other problem domains where they apply, so that such a platform might potentially be developed at far greater speed and scale, since much of this functionality already exists.

Components of the P2PSF are currently being elaborated in a whitepaper [6] describing the planned Initial Coin Offering (ICO) through which the P2PSF is intended to be launched. The current list of those components is listed in table 2.

Table 2. Required functionality for the Peer to Peer Social Fabric (P2PSF).

\begin{tabular}{ll}
\hline $\begin{array}{l}\text { Components of the } \\
\text { P2PSF }\end{array}$ & Description \\
\hline $\begin{array}{l}\text { Identity Management } \\
\text { (Identity Domain) }\end{array}$ & $\begin{array}{l}\text { A decentralized } \\
\text { store of identify } \\
\text { information to } \\
\text { open participation } \\
\text { to the most fit } \\
\text { participant rather } \\
\text { than limiting it to } \\
\text { any centralized } \\
\text { list. }\end{array}$ \\
& $\begin{array}{l}\text { A decentralized } \\
\text { information } \\
\text { Replication }\end{array}$ \\
$\begin{array}{l}\text { Management } \\
\text { (Replication Domain) }\end{array}$ & system. \\
\hline
\end{tabular}

Information An

Management implementation

(Information independent

Processing Domain) representation of information.

Context Management An

(Context Ownership implementation

Domain) independent representation of ownership.

\begin{tabular}{|c|c|}
\hline $\begin{array}{l}\text { Semantic Storage and } \\
\text { Recall (Storage } \\
\text { Domain) }\end{array}$ & $\begin{array}{l}\text { Storage of } \\
\text { information in } \\
\text { conceptual space. }\end{array}$ \\
\hline $\begin{array}{l}\text { Presentation } \\
\text { Management (Visual } \\
\text { Domain) }\end{array}$ & $\begin{array}{l}\text { An } \\
\text { implementation } \\
\text { independent } \\
\text { presentation layer. }\end{array}$ \\
\hline $\begin{array}{l}\text { Process Execution } \\
\text { Management } \\
\text { (Information } \\
\text { Processing Domain) }\end{array}$ & $\begin{array}{l}\text { Management } \\
\text { execution } \\
\text { business } \\
\text { application } \\
\text { processes. }\end{array}$ \\
\hline $\begin{array}{l}\text { Process Execution } \\
\text { Management (Other } \\
\text { Functional Domains) }\end{array}$ & $\begin{array}{l}\text { Management of } \\
\text { the execution of } \\
\text { processes in other }\end{array}$ \\
\hline
\end{tabular}




\begin{tabular}{|c|c|}
\hline & $\begin{array}{l}\text { functional } \\
\text { domains } \\
\text { generalized } \\
\text { domain that might } \\
\text { be consolidated } \\
\text { with some of the } \\
\text { domains below). }\end{array}$ \\
\hline $\begin{array}{l}\text { Application } \\
\text { Management } \\
\text { (Operating System } \\
\text { Domain) }\end{array}$ & $\begin{array}{l}\text { Management of } \\
\text { the execution of } \\
\text { processes in the } \\
\text { operating system } \\
\text { domain. }\end{array}$ \\
\hline $\begin{array}{l}\text { Hardware and IoT } \\
\text { Management } \\
\text { (Hardware Domain) }\end{array}$ & $\begin{array}{l}\text { Management of } \\
\text { the execution of } \\
\text { all functional } \\
\text { domains related to } \\
\text { IoT and other } \\
\text { hardware. }\end{array}$ \\
\hline $\begin{array}{l}\text { Security Management } \\
\text { (Security Domain) }\end{array}$ & $\begin{array}{l}\text { Management of } \\
\text { the execution of } \\
\text { the security } \\
\text { domain. }\end{array}$ \\
\hline $\begin{array}{l}\text { Communication } \\
\text { Management } \\
\text { (Communication } \\
\text { Domain) }\end{array}$ & $\begin{array}{l}\text { Management of } \\
\text { the execution of } \\
\text { the } \\
\text { communication } \\
\text { domain. }\end{array}$ \\
\hline $\begin{array}{l}\text { Cognitive Computing } \\
\text { (Intelligent Agent } \\
\text { Management) }\end{array}$ & $\begin{array}{l}\text { Management of } \\
\text { execution of } \\
\text { intelligent agents } \\
\text { representing each } \\
\text { user. }\end{array}$ \\
\hline $\begin{array}{l}\text { Collective Cognitive } \\
\text { Computing (General } \\
\text { Collective Intelligence } \\
\text { Management) }\end{array}$ & $\begin{array}{l}\text { Management of } \\
\text { execution of the } \\
\text { GCI. }\end{array}$ \\
\hline
\end{tabular}

Requirements for additional functionality might be discovered during the actual process of implementing the P2PSF. As mentioned, cognitive computing applications or platforms involve defining a functional model of processes within a given computing domain, and then using intelligent agents based on some subset of AGI functionality to execute those processes in a way that optimizes individual outcomes, or using GCI to execute those processes in a way that optimizes collective outcomes. The decoupling described above is required wherever some property of execution might be bound to an individual entity, and therefore centralized in the respect that this property might potentially be constrained in having to reflect that individual entity's interests. Whenever this is the case, that property must be decoupled from that constraint in order to achieve the goal of optimizing outcomes for other individuals, or maximizing collective outcomes.

One might assume that in a free market decoupling processes in this way is unnecessary because market forces ensure any product or service that is embraced by the market will be the one that serves the needs of the consumer to the maximum degree. However, this assumption requires the assumption of a perfectly efficient market. One might also assume that all entities orchestrating centrally controlled group processes are constrained to be self-less. However this assumes that all such controlling entities are perfectly knowledgeable in their understanding of what best serves the interests of every single individual, and therefore what maximizes collective interests. Even in the case of perfectly efficient free markets, and even in the case of controlling entities being perfectly self-less, according to this model of GCI understanding all possible options by which collective outcomes might be optimized is a larger problem than any individual entity has the capacity to solve, and therefore is a problem that requires GCI. No process run by any individual or group without GCI can reliably optimize outcomes achieved by cognitive computing applications or platforms otherwise.

\section{Infrastructure Required for Collectively Intelligent Cooperation}

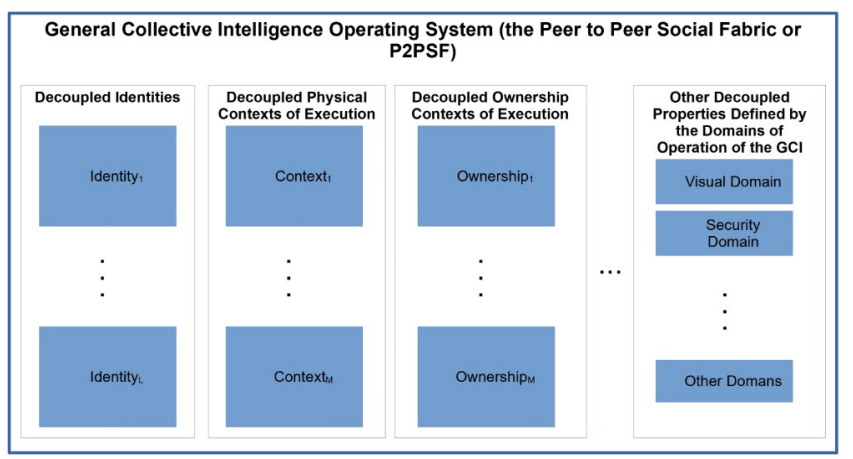


Figure 4. Infrastructure required for decoupling process execution, and therefore required for GCI..

\section{Findings}

The proposed Peer to Peer Social Fabric appears to meet the requirements of both the operating system for GCI, and a client enabling individuals and organizations to access AGI or GCI functionality

Table 3. Research Findings.

\begin{tabular}{|c|c|}
\hline Research Question & Findings \\
\hline $\begin{array}{l}\text { 1. What is the } \\
\text { functionality } \\
\text { required by an } \\
\text { infrastructure } \\
\text { platform with the } \\
\text { capacity to facilitate } \\
\text { the operations of } \\
\text { collective cognitive } \\
\text { computing } \\
\text { applications? }\end{array}$ & $\begin{array}{l}\text { 1. The functionality } \\
\text { appearing to be } \\
\text { required is to } \\
\text { decouple processes } \\
\text { from any property of } \\
\text { execution so } \\
\text { execution can be } \\
\text { optimized. }\end{array}$ \\
\hline $\begin{array}{l}\text { 2. Does the proposed } \\
\text { Peer to Peer Social } \\
\text { Fabric provide this } \\
\text { functionality? }\end{array}$ & $\begin{array}{l}\text { 2. Pending } \\
\text { confirmation through } \\
\text { actual } \\
\text { implementation, the } \\
\text { answer appears to be } \\
\text { yes. The P2PSF } \\
\text { appears to be capable } \\
\text { of both acting as a } \\
\text { client that connects } \\
\text { individuals to AGI or } \\
\text { GCI functionality, } \\
\text { and acting as the } \\
\text { operating system of } \\
\text { the GCI itself. }\end{array}$ \\
\hline
\end{tabular}

\section{Research Limitations}

Though a number of specific GCI based solutions such as a "Social Impact Marketplace" [13] have been designed to make use of a platform like the
P2PSF, they are still awaiting implementation. Additional missing details regarding the requirements of a P2PSF platform capable of acting as the infrastructure of a GCI will inevitably make themselves apparent at that time.

\section{Practical Implications}

In every application domain, cognitive computing based on AGI and collective cognitive computing based on GCI has the potential to significantly increase outcomes. As an example, in health care one conceptual case study currently under way explores the potential of GCI based platforms to reduce enough of the US $\$ 3.3$ trillion dollar health care budget per year to reduce health care costs and/or increase the quality of services available at the same cost, to a degree far greater than possible through any other means, regardless of whether a private or public single payer system is chosen, so that the cost savings alone might pay for universal health care for those without coverage. In education, renewable energy, design, smart manufacturing, and innumerable other areas, the same potential for GCI based platforms to significantly increase impact on targeted outcomes is currently being explored.

From the functional modelling perspective, any innate collective intelligence that groups have [16], [17], [18] might be modelled as executing a set of collective reasoning processes represented by some set of paths in the collective conceptual space. From this same perspective every Collective Intelligence (CI) solution [19], [20], [21], [22] is a tool that automates execution of some set of processes in the collective conceptual space. Implementing a General Collective Intelligence creates the potential to decouple such processes or software into a library that the GCI might use to significantly increase its general problem-solving ability through automating the execution of any such processes. A platform such as the P2PSF is likely required to have the capacity to automate execution of any such process.

\section{Recommendations for Future Work}


Each of the functional components of the proposed P2PSF represents a domain in which functional models must be elaborated. If all existing software implementing such functionality can be decomposed into such a common functional model in that domain, this suggests all existing solutions from all vendors in each domain might be added to a library that a GCI might use to optimize it's general problem-solving ability and hence performance in that domain. Since part of the functionality of this model of GCI is that required to determine which implementation of a given function is most fit within a given problem domain, such a functional modelling approach might effectively combine all research in each domain into a single meta-project with the potential to more rapidly and reliably converge on the functionality required to achieve any outcome in that domain. In order to achieve this functional models in each domain must be elaborated, and the model of GCI itself must be implemented. Some components of the GCI model need to be elaborated for this implementation to be possible, however an implemenatable approximation for GCI has been defined [15].

\section{Conclusions}

All collective problem-solving shares common infrastructure requirements in this model of GCI. While building this infrastructure might be outside of the budget of any single project, understanding how this infrastructure can be generalized to apply everywhere can potentially allow this functionality to be abstracted into a common platform such as the P2PSF, so that the cost of achieving these significant benefits can be shared.

As described elsewhere [11], GCI is a complex system that must likely in effect be grown through initiating a self-assembling process that adapts in any way required to maximize collective outcomes and to attract the resources to support such a large effort, rather than being developed in a top-down way that can become tightly coupled with centralized interests. Defining a simple functional model of GCI alone is not sufficient to implement GCI. An understanding of the selfreinforcing networks of cooperation and the hierarchy in which those networks must be deployed [12], the individualization that must be applied to products and services to leverage GCI [14], as well as the application to research, design and all the other processes in the business lifecycle, might all be required. However, understanding the infrastructure required to implement a GCI is one step, and the P2PSF appears to fit the requirements.

And if GCI has the potential to drive an exponential increase in ability to solve all problems then building such a general infrastructure platform might be more impactful than any other specific problems that a programmer might conceive of. From a functional modelling perspective general problem-solving ability is the capacity to navigate a given volume of conceptual space per unit time. If the set of solutions achievable with a particular computing program represents a set of paths through conceptual space, then the volume in conceptual space corresponding to such narrow problemsolving ability might resemble a narrow rod. If a super computer or even a quantum computing version of the program is a billion times faster, then the rod might be a billion times longer. The narrow problem-solving ability corresponding to the narrow volume in conceptual space that can be navigated might be correspondingly greater. However, an exponential increase in general problem-solving ability creates an exponential increase in ability to replicate that rod of narrow problem-solving ability in all directions, including to the problem of designing a better quantum computer as well.

\section{Acknowledgements.}

Thanks to Julian Talev for countless discussions on the topic.

\section{References}


1 Conference: The Relationship Between Collective Intelligence and One Model of General Collective Intelligence, Andy E. Williams, Computational Collective Intelligence, 11th International Conference, ICCCI 2019, Hendaye, France, September 4-6, 2019, Proceedings, Part II, Pages 589600

2 Pre-print: Williams, A. E. (2020, April 30). A Model for General Collective Intelligence. https://doi.org/10.31730/osf.io/6u984

3 Pre-print: Williams, A. E. (2020, May 15). Use of Human-Centric Functional Modeling to Maximize Convergence in Integrative Research. https://doi.org/10.31730/osf.io/jv6h8

4 Book Chapter: Williams A.E. (2020) A Model for Artificial General Intelligence. In: Goertzel B., Panov A., Potapov A., Yampolskiy R. (eds) Artificial General Intelligence. AGI 2020. Lecture Notes in Computer Science, vol 12177. Springer, Cham. https://doi.org/10.1007/978-3-030-52152-

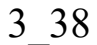

5 Pre-print: Williams, A. E. (2020, July 11). Human Intelligence and General Collective Intelligence as Phase Changes in Animal Intelligence. https://doi.org/10.31234/osf.io/dr8qn

6 Pre-print: Andy E. Williams, Roberto Moro visconti, Andy E. Williams, The Application of Artificial General Intelligence to the Cognitive Blockchain and the Internet of Value, DOI: 10.13140/RG.2.2.15004.31363

7 Pre-print: Williams, A. E. (2020, December 2). General Collective Intelligence vs the Innate Collective Intelligence Factor. https://doi.org/10.31730/osf.io/kp3x8

8 Journal article: Krafft, P.M. (2019), A Simple Computational Theory of General Collective Intelligence. Top Cogn Sci, 11: 374-392. https://doi.org/10.1111/tops.12341.

9 Journal article: Woolley, Anita Williams; Chabris, Christopher F.; Pentland, Alex; Hashmi, Nada; Malone, Thomas W. (29 October 2010). "Evidence for a Collective Intelligence Factor in the Performance of Human Groups". Science. 330 (6004): 686-688. Bibcode:2010Sci...330..686W. doi:10.1126/science.1193147. PMID 20929725. S2CID 74579.

10 Book: Malone, T. W. (2018). Superminds: The surprising power of people and computers thinking together.

11 Pre-print: Williams, A. E. (2020, November 11). General Collective Intelligence and the Transition to Collective Super-Intelligence. https://doi.org/10.31730/osf.io/tacyq Under review (2020)

12 Pre-print: Williams, A. E. (2020, December 16). Discovering and Implementing Self-Sustaining Networks of Cooperation with General Collective Intelligence. https://doi.org/10.31730/osf.io/safxk

13 Pre-print: Williams, A. E. (2020, April 30). The Collective Intelligence based Program to Accelerate Achievement of the Sustainable Development Goals as a Case Study for Collectively Intelligent Program Design. https://doi.org/10.31235/osf.io/r2dxq

14 Pre-print: Williams, A. E. (2020, December 16). Individualization of Products and Services with Artificial General Intelligence and General Collective Intelligence. https://doi.org/10.31730/osf.io/gd5mt

15 Pre-print: Williams, A. E. (2021, January 11). Approximating an Artificial General Intelligence or a General Collective Intelligence. https://doi.org/10.31730/osf.io/zsbfe

16 Journal article: Woolley, Anita Williams, Yeonjeong Kim, and Thomas W. Malone. "Measuring collective intelligence in groups: a reply to credé and howardson." June 1 (2018): 5431-18.

17 Journal article: Woolley, Anita Williams, Ishani Aggarwal, and Thomas W. Malone. "Collective intelligence and group performance." Current Directions in Psychological Science 24.6 (2015): 420424.

18 Journal article: Barlow, Jordan B., and Alan R. Dennis. "Not as smart as we think: A study of collective intelligence in virtual groups." Journal of Management Information Systems 33.3 (2016): 684-712. 
19 Journal article: Suran, Shweta, Vishwajeet Pattanaik, and Dirk Draheim. "Frameworks for collective intelligence: a systematic literature review." ACM Computing Surveys (CSUR) 53.1 (2020): 1-36.

20 Journal article: Yu, Chao, Yueting Chai, and Yi Liu. "Literature review on collective intelligence: a crowd science perspective." International Journal of Crowd Science (2018).

21 Journal article: Cremona, Luca, and Aurelio Ravarini. "Collective intelligence and social computing: a literature review." Information systems: crossroads for organization, management, accounting and engineering (2012): 35-41.

22 Journal article: Sadasivam, Rajani Shankar, et al. "Collective-intelligence recommender systems: advancing computer tailoring for health behavior change into the 21 st century." Journal of medical Internet research 18.3 (2016): e42.

23 Journal article: Dornhaus, Anna, and Nigel R. Franks. "Individual and collective cognition in ants and other insects (Hymenoptera: Formicidae)." Myrmecol. News 11.August (2008): 215-226

24 Journal article: West III, G. Page. "Collective cognition: When entrepreneurial teams, not individuals, make decisions." Entrepreneurship Theory and Practice 31.1 (2007): 77-102.

25 Journal article: Gibson, Cristina B. "From knowledge accumulation to accommodation: Cycles of collective cognition in work groups." Journal of Organizational Behavior: The International Journal of Industrial, Occupational and Organizational Psychology and Behavior 22.2 (2001): 121-134. 